\title{
Impaired Humoral Response in Renal Transplant Recipients to SARS-CoV-2 Vaccination with BNT162b2 (Pfizer-BioNTech)
}

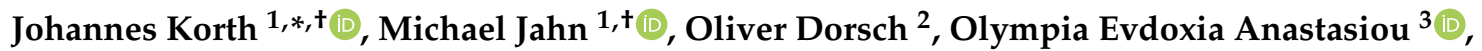 \\ Burkhard Sorge-Hädicke ${ }^{4}$, Ute Eisenberger ${ }^{1}{ }^{\mathbb{D}}$, Anja Gäckler ${ }^{1}$, Ulf Dittmer ${ }^{3}$, Oliver Witzke ${ }^{5}$, Benjamin Wilde ${ }^{1}$, \\ Sebastian Dolff ${ }^{5, \mp(1)}$ and Andreas Kribben ${ }^{1, \ddagger}$
}

check for updates

Citation: Korth, J.; Jahn, M.; Dorsch, O.; Anastasiou, O.E.; Sorge-Hädicke, B.; Eisenberger, U.; Gäckler, A.; Dittmer, U.; Witzke, O.; Wilde, B.; et al. Impaired Humoral Response in Renal Transplant Recipients to SARS-CoV-2 Vaccination with BNT162b2 (Pfizer-BioNTech). Viruses 2021, 13, 756. https://doi.org/ $10.3390 /$ v13050756

Academic Editor: Oscar R. Burrone

Received: 19 March 2021

Accepted: 22 April 2021

Published: 25 April 2021

Publisher's Note: MDPI stays neutral with regard to jurisdictional claims in published maps and institutional affiliations.

Copyright: (c) 2021 by the authors. Licensee MDPI, Basel, Switzerland. This article is an open access article distributed under the terms and conditions of the Creative Commons Attribution (CC BY) license (https:/ / creativecommons.org/licenses/by/ $4.0 /)$.
1 Department of Nephrology, University Hospital Essen, University of Duisburg-Essen, Hufelandstr. 55, 45147 Essen, Germany; michael.jahn@uk-essen.de (M.J.); ute.eisenberger@uk-essen.de (U.E.); anja.gackler@uk-essen.de (A.G.); Benjamin.wilde@uk-essen.de (B.W.); andreas.kribben@uk-essen.de (A.K.)

2 KfH Kuratorium für Dialyse und Nierentransplantation e.V, KfH-Nierenzentrum Friesener Straße 37a, 96317 Kronach, Germany; oliver.dorsch@kfh.de

3 Institute for Virology, University Hospital Essen, University of Duisburg-Essen, Virchowstr. 179, 45147 Essen, Germany; olympiaevdoxia.anastasiou@uk-essen.de (O.E.A.); ulf.dittmer@uk-essen.de (U.D.)

$4 \mathrm{KfH}$ Kuratorium für Dialyse und Nierentransplantation e.V, KfH-Nierenzentrum Alfried-Krupp-Str. 43, 45131 Essen, Germany; burkhard.sorge-haedicke@kfh-dialyse.de

5 Department of Infectious Diseases, West German Centre of Infectious Diseases, University Hospital Essen, University of Duisburg-Essen, Hufelandstr. 55, 45147 Essen, Germany; oliver.witzke@uk-essen.de (O.W.); sebastian.dolff@uk-essen.de (S.D.)

* Correspondence: johannes.korth@uk-essen.de; Tel.: +49-201-723-84622

+ These authors contributed equally to this work.

$\ddagger$ shared last author.

Abstract: The severe acute respiratory syndrome coronavirus-2 (SARS-CoV-2) has a major impact on transplant recipients, with mortality rates up to $20 \%$. Therefore, the effect of established messenger RNA (mRNA)-based SARS-CoV-2 vaccines have to be evaluated for solid organ transplant patients (SOT) since they are known to have poor responses after vaccination. We investigated the SARSCoV-2 immune response via SARS-CoV-2 IgG detection in 23 renal transplant recipients after two doses of the mRNA-based SARS-CoV-2 vaccine BNT162b2 following the standard protocol. The antibody response was evaluated once with an anti-SARS-CoV-2 IgG CLIA $15.8+$ / - 3.0 days after the second dose. As a control, SARS-CoV-2 IgG was determined in 23 healthcare workers (HCW) and compared to the patient cohort. Only 5 of $23(22 \%)$ renal transplant recipients were tested positive for SARS-CoV-2 IgG antibodies after the second dose of vaccine. In contrast, all 23 (100\%) HCWs were tested positive for antibodies after the second dose. Thus, the humoral response of renal transplant recipients after two doses of the mRNA-based vaccine BNT162b2 (Pfizer-BioNTech, Kronach, Germany) is impaired and significantly lower compared to healthy controls (22\% vs. $100 \%$; $p=0.0001$ ). Individual vaccination strategies might be beneficial in these vulnerable patients.

Keywords: SARS-Cov-2 vaccination; renal transplant recipients; renal transplantation; COVID-19

\section{Introduction}

The novel severe acute respiratory syndrome coronavirus-2 (SARS-CoV-2) is a major threat to solid organ transplant recipients (SOT) with a mortality rate of up to $20 \%[1,2]$. Currently there is a lack in efficient treatment options [3]. New messenger RNA (mRNA)based SARS-CoV-2 vaccines were evaluated in over 70,000 individuals and found to have an efficacy of $95 \%$ in phase 3 placebo-controlled trials [4,5]. Since December 2020, the European union approved the first mRNA-based SARS-CoV-2 vaccine of Pfizer-BioNTech (https: / / www.pei.de/DE/home/home-node.html, accessed on 21 December 2020). Immunocompromised patients, like SOT recipients were not included in the large phase 3 trials, and therefore, efficacy data are lacking. However, vaccination is recommended 
for SOT patients in Germany [6,7]. The current study evaluates the immune response of 23 renal transplant recipients after standard vaccination protocol with two vaccinations with the mRNA-based SARS-CoV-2 vaccine BNT162b2 (Pfizer-BioNTech, Nierenzentrum Kronach) in January and February 2021 by SARS-CoV-2 IgG development. The results were compared to the antibody response of 23 healthcare workers vaccinated using the same standard protocol with the same vaccine [8].

\section{Materials and Methods}

Twenty-three renal transplant recipients of the Nierenzentrum Kronach, Germany were intramuscularly vaccinated twice with a gap of $22.0+/-4.6$ days between the shots with the mRNA-based SARS-CoV-2 vaccine BNT162b2 (Pfizer-BioNTech) according to the standard protocol at a vaccination center in Kronach, Germany [9]. Fourteen days after the second vaccination serum samples were tested for SARS-CoV-2 IgG against the Spike glycoprotein using an approved anti-SARS-CoV-2 IgG CLIA (LIAISON ${ }^{\circledR}$ SARSCoV-2 TrimericS IgG assay, Diasorin, Saluggia, Italy). According to the manufacturer's recommendations for the Chemiluminescence Enzyme Immunoassays (CLIA), an Arbitrary Units per milliliter $(\mathrm{AU} / \mathrm{mL}$ ) ratio of $<13.0$ was considered to be negative and $\geq 13.0$ to be positive. A conversion of $\mathrm{AU} / \mathrm{mL}$ to binding antibody units $(\mathrm{BAU} / \mathrm{mL})$ that correlate with the WHO standard is possible using the following equation: $\mathrm{BAU} / \mathrm{mL}=2.6^{*} \mathrm{AU} / \mathrm{mL}$. $800.0 \mathrm{AU} / \mathrm{mL}(2080 \mathrm{BAU} / \mathrm{mL})$ is the upper limit of quantification without dilution of the CLIA.

In addition, the antibody response was compared to 23 healthcare workers after two intramuscular vaccinations at the University Hospital Essen in January 2021 with the same vaccination, sampling and testing protocol as the renal transplant recipients. The HCW received regular testing with teal-time PCR-assays for SARS-CoV-2 RNA from nasal swabs and had no clinical suspicion for SARS-CoV-2 infections throughout the preceding 12 months. Since the current study was focused on the humoral immune response in renal transplant patients, T-cell activity was not evaluated in this study. Fisher's exact test and Mann-Whitney $\mathrm{U}$ test was used to compare the results between groups.

\section{Results}

Of the 23 renal transplant recipients included in the study, none had a prior or current diagnosis of COVID-19. The mean age was $57.7+/-13.5$ years. Twelve $(52 \%)$ of the 23 patients were female and $11(48 \%)$ were male. The mean time after renal transplantation was $11.4+/-9.2$ years. The immunosuppressive regimen included mycophenolate (18 of $23 ; 78 \%$ ), tacrolimus (14 of $23 ; 60 \%$ ) and corticosteroids (14 of $23 ; 60 \%$ ) (Table 1$)$. None of the $23 \mathrm{HCW}$ had a confirmed diagnosis of COVID-19 prior to the vaccination. The mean age was $44.4+/-9.2$ years. Fourteen $(61 \%)$ were female and $9(39 \%)$ were male. Five of $23(22 \%)$ renal transplant recipients tested positive for SARS-CoV-2 IgG at a mean of $15.8+/-3.0$ days after the second dose of vaccine (Table 1). The mean SARS-CoV-2 IgG titer was $50.9+/-138.7 \mathrm{AU} / \mathrm{mL}$.

All $23(100 \%)$ HCW tested positive for SARS-CoV-2 IgG at a mean of $13.7+/-1.8$ days after the second dose. The mean SARS-CoV-2 IgG titer was $727.7+/-151.3 \mathrm{AU} / \mathrm{mL}$.

The immunosuppressive regimens in patients who tested positive and negative for SARS-CoV-2 IgG antibodies after vaccination were similar and there were no differences in age, gender and immunosuppressive drugs between these groups of patients (Table 2). 
Table 1. Characteristics of patients after renal transplantation and healthcare workers after two doses of the mRNA-based SARS-CoV-2 vaccine BNT162b2. rtx renal transplant recipients; HCW, healthcare workers; n number; pos positive; neg negative; $\mathrm{Ab}$ antibody, CLIA Chemiluminescence Enzyme Immunoassays; AU Arbitrary Units; mL milliliter; Ab antibody.

\begin{tabular}{|c|c|c|c|}
\hline & rtx & HCW & \\
\hline $\mathbf{n}$ & 23 & 23 & $p$ \\
\hline female/male (n; \%) & $12(52 \%) / 11(48 \%)$ & $14(61 \%) / 9(39 \%)$ & 0.76 \\
\hline age (years) & $57.7+/-13.5$ & $44.4+/-9.2$ & 0.0003 \\
\hline immunosuppression (n) & & \multirow{9}{*}{ - } & \\
\hline mycophenolate n (\%) & $18,(78 \%)$ & & \\
\hline corticosteroids n (\%) & $14(60 \%)$ & & \\
\hline tacrolimus n (\%) & $14(60 \%)$ & & \\
\hline cyclosporine $\mathrm{n}(\%)$ & $4(17 \%)$ & & \\
\hline sirolimus n (\%) & $5(22 \%)$ & & \\
\hline everolimus $\mathrm{n}(\%)$ & $1(4 \%)$ & & \\
\hline belatacept n (\%) & $1(4 \%)$ & & \\
\hline azathioprine $\mathrm{n}(\%)$ & $1(4 \%)$ & & \\
\hline years after rtx & $11.4+/-9.2$ & - & \\
\hline days between first and second dose (days) & $22.0+/-4.6$ & $22.0+/-0$ & \\
\hline $\begin{array}{c}\text { SARS-CoV-2 Ab detection after second } \\
\text { dose (days) }\end{array}$ & $15.8+/-3.0$ & $13.7+/-1.8$ & \\
\hline SARS-CoV-2 Ab posCLIA (n; \%) & $5(22 \%)$ & $23(100 \%)$ & \multirow{2}{*}{0.0001} \\
\hline SARS-CoV-2 Ab negCLIA (n; \%) & $18(78 \%)$ & $0(0 \%)$ & \\
\hline Ab SARS-COV-2 CLIA (AU/mL) & $50.9+/-138.7$ & $727.7+/-151.3$ & 0.0001 \\
\hline
\end{tabular}

Table 2. Characteristics of renal transplant recipients who tested positive and negative for SARS.CoV2 IgG after two doses of the mRNA-based SARS-CoV-2 vaccine BNT162b2.

\begin{tabular}{ccc}
\hline & SARS-CoV-2 IgG Positive & SARS-CoV-2 IgG Negative \\
\hline $\mathbf{n}$ & 5 & 18 \\
\hline female/male $\mathbf{n}(\%)$ & $3(60 \%) / 2(40 \%)$ & $9(50 \%) / 9(50 \%)$ \\
\hline age (years) & $57.0+/-8.1$ & $57.9+/-14.9$ \\
\hline time after rtx (years) & $17.6+/-7.7$ & $9.7+/-9.1$ \\
\hline mycophenolate $\mathbf{n}(\%)$ & $3(60 \%)$ & $15(83 \%)$ \\
\hline corticosteroids $\mathbf{n}(\%)$ & $3(60 \%)$ & $11(61 \%)$ \\
\hline tacrolimus $\mathbf{n}(\%)$ & $2(40 \%)$ & $12(67 \%)$ \\
\hline cyclosporine $\mathbf{n}(\mathbf{\%})$ & $2(40 \%)$ & $2(11 \%)$ \\
\hline sirolimus $\mathbf{n}(\%)$ & $1(20 \%)$ & $4(22 \%)$ \\
\hline everolimus $\mathbf{n}(\%)$ & $1(20 \%)$ & $1(6 \%)$ \\
\hline betalacept $\mathbf{n}(\mathbf{\%})$ & 0 & $1(6 \%)$ \\
\hline azathioprine $\mathbf{n}(\%)$ & 0 & $2.6+/-0.5$ \\
\hline $\begin{array}{c}\text { number } \text { of immunosuppressive } \\
\text { drugs } \mathbf{n}(\%)\end{array}$ & $2.4+/-0.5$ &
\end{tabular}

The proportion of renal transplant recipients testing positive for antibodies after protocol-based vaccination was significantly lower in comparison to the control group of HCW (22\% vs. $100 \%, p=0.0001$, Figure 1$)$. In addition, the mean SARS-CoV-2 antibody titer of the renal transplant recipients was significantly lower in comparison to the HCW (50.9 +/ - 138.7 AU/mL vs. $727.7+/-151.3 \mathrm{AU} / \mathrm{mL}, p=0.0001)$. 


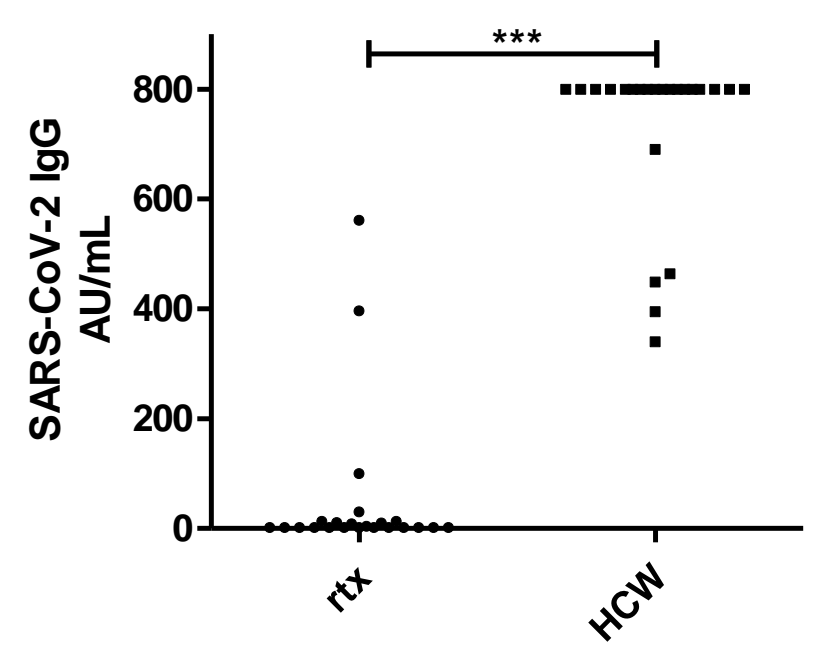

Figure 1. IgG Chemiluminescence Enzyme Immunoassays (CLIA) Arbitrary Units per milliliter $(\mathrm{AU} / \mathrm{mL})$ ratio in 23 renal transplant recipients $(\mathrm{rtx})$ and 23 healthcare workers (HCW) after two doses of the mRNA-based SARS-CoV-2 vaccine BNT162b2. ${ }^{* * *} p<0.0001$.

\section{Discussion}

This is the first study which evaluates the immune response of 23 renal transplant recipients after standard protocol-based vaccination of two doses of the mRNA-based SARS-CoV-2 vaccine BNT162b2. The immune response was evaluated by SARS-CoV-2 IgG anti-Trimeric Spike glycoprotein detection $15.8+/-3.0$ days after the second dose of the vaccine. The results were compared to a control group of 23 healthy healthcare workers after using the same standard protocol with two doses of the same mRNA-based SARS-CoV-2 vaccine BNT162b2. Only 5 of the $23(22 \%)$ renal transplant recipients tested positive for SARS-CoV-2 IgG antibodies after vaccination. In comparison all the $23 \mathrm{HCW}$ $(100 \%)$ tested positive for SARS-CoV-2 IgG antibodies after vaccination ( $22 \%$ vs. $100 \%$, $p=0.0001$ ). In addition, the mean SARS-CoV-2 IgG titer of renal transplant recipients was significantly lower $(50.9+/-138.7$ vs. $727.7+/-151.3, p=0.0001)$. The data exposes the impaired immune response of solid organ transplant (SOT) patients after standard mRNA-based SARS-CoV-2 vaccination. It is likely that SOT patients need an individualized vaccination scheme. This may include more than two booster doses or even a combined scheme with mRNA vaccines, protein/subunit vaccines and vector-based vaccines. The findings are in line with the impaired responses to other vaccination in patients after SOT and is most likely due to immunosuppression [10]. Our results are concordant with those from a recently published study by Boyarsky et al., which evaluated immunogenicity in 436 SOT after one dose of an mRNA-based vaccine. The authors observed that only 76 of 436 of the SOT patients (17\%) had a positive antibody response [11]. In addition a recently published study by Chavarot and colleagues evaluated the IFN $\gamma$ T-cell responses after two injections of an mRNA vaccine in kidney transplant recipients treated with belatacept [12]. The authors reported a low seroconversion rate at day 60 and a T-cell response in only $30.4 \%$ of the patients measured. The current data suggest that these patients might be vulnerable for COVID-19 disease in spite of their vaccination status, since reliable immunization after protocol-based vaccination with the mRNA-based SARS-CoV-2 vaccine BNT162b2 was not verifiable. It might be possible that other approved vaccines such as vector-based vaccines induce better humoral responses, but further studies are needed to address this issue. A limitation of the present study is the lack of results regarding SARS-CoV-2 specific T-cell response and neutralization capacity of the sera, which could counterbalance the impaired humoral response. In clinical practice, booster doses or higher initial dosages might improve the immune response in SOT patients such as in diphtheria, hepatitis B or pneumococcal vaccination $[13,14]$. 


\section{Conclusions}

In conclusion, the detectable humoral immune response after standard protocol vaccination with two doses of the mRNA-based SARS-CoV-2 vaccine BNT162b2 in 22\% of all renal transplant patients is poor. We suggest that renal transplant recipients should be monitored for immune responses, and novel individual vaccination strategies might be needed and evaluated in clinical trials in this vulnerable cohort. Nevertheless, studies with more participants and various vaccine candidates are needed to evaluate the different effects and further immune responses like B-and T-cell responses in patients after SOT.

Author Contributions: Conceptualization, J.K., O.D., M.J., B.W., S.D. and A.K.; methodology, O.D., O.W. and B.S.-H.; validation, O.E.A., U.D., U.E., A.G. and B.W.; formal analysis, J.K., M.J. B.W., O.D. and A.K.; writing - original draft preparation, J.K., M.J., B.W., S.D. and A.K.; project administration, J.K.; All authors have read and agreed to the published version of the manuscript.

Funding: This research received no external funding.

Institutional Review Board Statement: The study was conducted according to the guidelines of the Declaration of Helsinki and approved by the ethics committee of the Medical Faculty of the University Duisburg-Essen (20-9753-BO).

Informed Consent Statement: Informed consent was obtained from all subjects involved in the study.

Data Availability Statement: The data that support the findings of this study are available from the corresponding author upon reasonable request.

Acknowledgments: The authors would like to thank Hannah Pfeng, Assia Omairatte, Emel Karaca Rebecca Blinzler and Christiane Kautsch for excellent assistance. Oliver Witzke is supported by an unrestricted grant of the Rudolf-Ackermann-Stiftung (Stiftung für Klinische Infektiologie). We acknowledge support by the Open Access Publication Fund of the University of Duisburg-Essen.

Conflicts of Interest: The other authors declared no conflict of interests.

\section{References}

1. Kates, O.S.; Haydel, B.M.; Florman, S.S.; Rana, M.M.; Chaudhry, Z.S.; Ramesh, M.S.; Safa, K.; Kotton, C.N.; Blumberg, E.A.; Besharatian, B.D.; et al. Coronavirus Disease 2019 in Solid Organ Transplant: A Multicenter Cohort Study. Clin. Infect. Dis. 2020, 1-14. [CrossRef]

2. Hugo, C.; Stecher, M.; Dolff, S.; Nattermann, J.; Vehreschild, J.; Hippchen, T.; Westhoff, T.; Bertolo, M.; Hohenstein, B.; Hanses, F.; et al. Solid organ transplantation is not a risk factor for COVID-19 disease outcome. Transpl. Int. 2021, 34, 378-381. [CrossRef] [PubMed]

3. Horby, P.; Lim, W.S.; Emberson, J.R.; Mafham, M.; Bell, J.L.; Linsell, L.; Staplin, N.; Brightling, C.; Ustianowski, A.; Elmahi, E.; et al. Dexamethasone in Hospitalized Patients with Covid-19_Preliminary Report. N. Engl. J. Med. 2020. [CrossRef]

4. Walsh, E.E.; Frenck, R.W.; Falsey, A.R.; Kitchin, N.; Absalon, J.; Gurtman, A.; Lockhart, S.; Neuzil, K.; Mulligan, M.J.; Bailey, R.; et al. Safety and Immunogenicity of Two RNA-Based Covid-19 Vaccine Candidates. N. Engl. J. Med. 2020, 383, $2439-2450$. [CrossRef] [PubMed]

5. Anderson, E.J.; Rouphael, N.G.; Widge, A.T.; Jackson, L.A.; Roberts, P.C.; Makhene, M.; Chappell, J.D.; Denison, M.R.; Stevens, L.J.; Pruijssers, A.J.; et al. Safety and Immunogenicity of SARS-CoV-2 mRNA-1273 Vaccine in Older Adults. N. Engl. J. Med. 2020, 383, 2427-2438. [CrossRef] [PubMed]

6. Stufenplan der STIKO zur Priorisierung der COVID-19-Impfung Hinweise zum Stufenplan der STIKO zur Priorisierung der COVID-19-Impfung. Robert Koch Institute. 2021. Available online: https://www.rki.de/DE/Content/Infekt/Impfen/ ImpfungenAZ/COVID-19/Stufenplan.pdf?_blob=publicationFile (accessed on 17 February 2021).

7. The German Ethics Council. The National Academy of Sciences Leopoldina Position Paper of the Joint Working Group of Members of the Standing Committee on Vaccination. How should Access to a COVID-19 Vaccine be Regulated; The German Ethics Council: Berlin, Germany, 2020; pp. 1-6.

8. Korth, J.; Wilde, B.; Dolff, S.; Anastasiou, O.E.; Krawczyk, A.; Jahn, M.; Cordes, S.; Ross, B.; Esser, S.; Lindemann, M.; et al. SARS-CoV-2-specific antibody detection in healthcare workers in Germany with direct contact to COVID-19 patients. J. Clin. Virol. 2020, 128, 104437. [CrossRef] [PubMed]

9. Polack, F.P.; Thomas, S.J.; Kitchin, N.; Absalon, J.; Gurtman, A.; Lockhart, S.; Perez, J.L.; Marc, G.P.; Moreira, E.D.; Zerbini, C.; et al. Safety and Efficacy of the BNT162b2 mRNA Covid-19 Vaccine. N. Engl. J. Med. 2020, 383, 2603-2615. [CrossRef] [PubMed]

10. Eckerle, I.; Rosenberger, K.D.; Zwahlen, M.; Junghanss, T. Serologic Vaccination Response after Solid Organ Transplantation: A Systematic Review. PLoS ONE 2013, 8, e56974. [CrossRef] [PubMed] 
11. Boyarsky, B.J.; Werbel, W.A.; Avery, R.K.; Tobian, A.A.R.; Massie, A.B.; Segev, D.L.; Garonzik-Wang, J.M. Immunogenicity of a Single Dose of SARS-CoV-2 Messenger RNA Vaccine in Solid Organ Transplant Recipients. JAMA. Available online: https://jamanetwork.com/journals/jama/article-abstract/2777685 (accessed on 15 March 2021).

12. Chavarot, N.; Ouedrani, A.; Marion, O.; Leruez-Ville, M.; Villain, E.; Baaziz, M.; Del Bello, A.; Burger, C.; Sberro-Soussan, R.; Martinez, F.; et al. Poor Anti-SARS-CoV-2 Humoral and T-cell Responses After 2 Injections of mRNA Vaccine in Kidney Transplant Recipients Treated with Belatacept. Transplantation. Available online: https://journals.lww.com/transplantjournal/ citation/9000/poor_anti_sars_cov_2_humoral_and_t_cell_responses.95281.aspx (accessed on 8 April 2021). [CrossRef]

13. Duchini, A.; Goss, J.A.; Karpen, S.; Pockros, P.J. Vaccinations for adult solid-organ transplant recipients: Current recommendations and protocols. Clin. Microbiol. Rev. 2003, 16, 357-364. [CrossRef] [PubMed]

14. Oesterreich, S.; Lindemann, M.; Goldblatt, D.; Horn, P.A.; Wilde, B.; Witzke, O. Humoral response to a 13-valent pneumococcal conjugate vaccine in kidney transplant recipients. Vaccine 2020, 38, 3339-3350. [CrossRef] [PubMed] 